
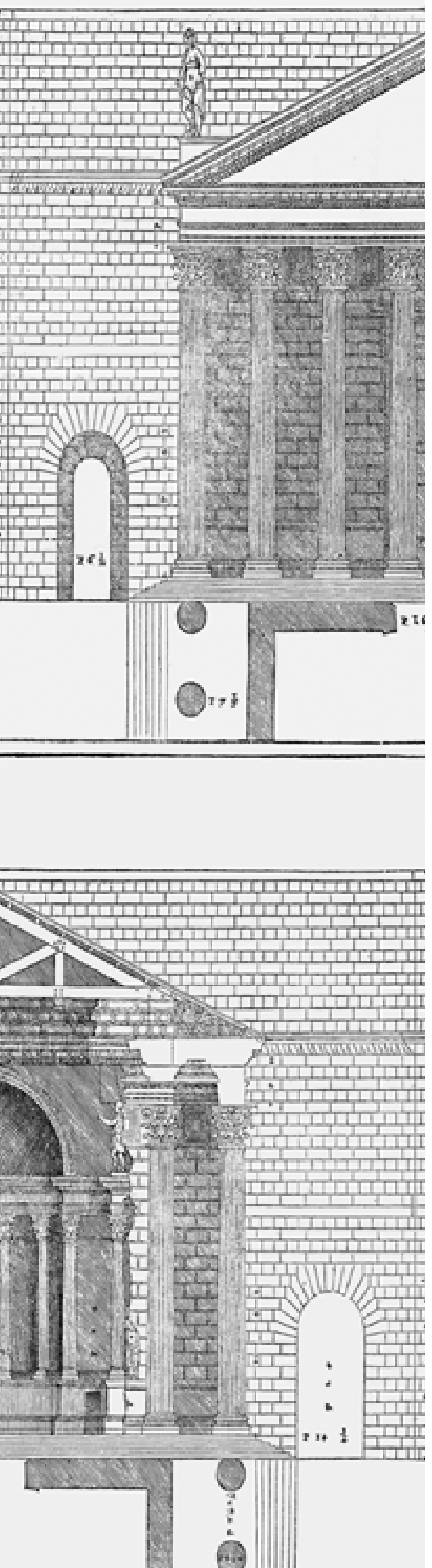

Intervención (ISSN-2448-5934), julio-diciembre 2018, año 9, núm.18: 6-20. DOI: $10.30763 /$ Intervencion.2018.17.196

\title{
El fragmento, la memoria y el disegno en I quattro libri dell'architettura de Andrea Palladio: tradición, invención e innovación
}

The Fragment, Memory and Disegno in Andrea Palladio's I quattro libri dell'architettura: Tradition, Invention and Innovation

Gabriela Solís Rebolledo

Facultad de Arquitectura (FA),

Centro de Investigaciones en Arquitectura, Urbanismo y Paisaje (CIAUP), Universidad Nacional Autónoma de México (UNAM), México gabrielasolis7335@yahoo.com.mx

\section{Resumen}

En la teoría arquitectónica del Cinquecento se fundamentó el proceso creativo a partir del principio italiano de disegno. Con base en ello, el propósito de este estudio se centra en la reflexión de dicha concepción en la teoría, arquitectura y dibujos de Andrea Palladio, con énfasis en el estrecho vínculo entre tradición e innovación. Ese aspecto ha sido poco estudiado respecto de la noción humanista del disegno, por lo que es necesario llevar a cabo no sólo una investigación bajo el marco de la teoría arquitectónica palladiana, sino también un estudio sobre el legado de la Antigüedad en dicho arquitecto como patrimonio material e inmaterial en relación con la trascendencia de las ideas y como referencia conceptual para su pensamiento y su arquitectura. Con ello se indagará si el concepto de disegno puede plantearse como modelo paradigmático del proceso proyectual de la forma respecto de la invención arquitectónica, la afinidad electiva y la estética de la empatía en la arquitectura.

\section{Palabras clave}

Andrea Palladio; arquitectura; diseño; fragmento; memoria; Italia

\section{Abstract}

In Cinquecento architectural theory, the creative process was based on the Italian principle of $\mathrm{di}^{-}$ segno. On this basis, the purpose of this study is to reflect on this conception in the theory, architecture, and drawings of Andrea Palladio, placing emphasis on the narrow link between tradition and innovation. There are few studies regarding this aspect concerning the humanist notion of $d i-$ segno. Thus, it is not only necessary to carry out research in the framework of Palladian architec- 
tural theory, but also a study on the legacy of Antiquity in said architect as tangible and intangible heritage related to the transcendence of ideas and as conceptual reference for his thinking and architecture. With this, we will investigate whether the concept of disegno can be considered a paradigmatic model of the design process of form with respect to architectural invention, elective affinity, and the aesthetics of empathy in architecture.

\section{Keywords}

Andrea Palladio; architecture; design; fragment; memory; Italy

\section{Introducción}

El legado de la Antigüedad: renovatio en el siglo XVI italiano

E I legado de la Antigüedad clásica, en razón del valor histórico de sus logros, y la definición del proceso creativo fueron dos aspectos que marcaron la teoría y la praxis arquitectónica del Renacimiento italiano. Una transformación tan profunda para la elaboración de una teoría del diseño arquitectónico en este contexto intelectual implicó la búsqueda tanto del pensamiento y el arte de la tradición grecolatina como del lenguaje específico del arquitecto para conceptualizar y expresar el proceso de composición de la forma, conocimientos que en los siglos XV y XVI se consideraban inseparables (cfr. Argan 1946: 96-121; Tobin 1979; Warburg 2005; Solís 2015).

Los humanistas del Renacimiento, contemplándose sobre el fondo de la herencia clásica, reconstruyeron sistemáticamente el proceso creativo a partir de los escritos de la tradición grecolatina, en especial, de los textos de Cicerón y Vitruvio (cfr. Lücke 1994: 70-95; Payne 1999: 34-88; Cellauro 2004: 293-329). Dicho proceso se basó en la idea de la renovatio de la Antigüedad entendida, en términos de la relación tradición-innovación, de dos maneras. ${ }^{1}$ La primera concierne al conocimiento del arte y el diálogo entre las disciplinas con énfasis en la unificación del saber. Esto es, principios y términos comunes que se establecieron como modelo de razonamiento y método de conocimiento, lo que generó un lenguaje propio para la arquitectura. Tal conocimiento les permitió plantear los conceptos del proceso proyectual en la teoría arquitectónica, el cual se formuló en el Cinquecento con base en el principio italiano de disegno. ${ }^{2}$ La segunda fue

\footnotetext{
1 La idea de renovatio fue concebida por Petrarca, quien elaboró una teoría de la historia dividida en dos periodos: el clásico y el reciente, pues imaginaba la nueva etapa en términos de regeneración, comprendida como el estudio e investigación cultural de la Antigüedad (cfr. Panofsky 1975: 42-53, 62-74).

${ }^{2}$ Se ha preferido no traducir el término disegno, ya que en la teoría arquitectónica del siglo XVı italiano tiene un significado más amplio; si
}

como investigación y estudio de las fuentes literarias y de los monumentos de la Antigüedad a través de los cuales se extrajeron modelos para la creación de formas nuevas. Este pensamiento y preocupación humanista se desarroIló en el contexto cultural del Véneto de Andrea Palladio (Wittkower 1988: 35, 85-137).

En ese sentido, el propósito aquí es reflexionar sobre esta línea de pensamiento en Palladio en conexión con el término disegno que utilizó en su tratado I quattro libri dell'architettura y en su praxis arquitectónica como interpretación de dicho conocimiento clásico (Palladio 1980 [1570]). Lo anterior permite sugerir que esta concepción llevó a los artistas del Renacimiento a pensarse a sí mismos como herederos de la Antigüedad y plantear que debido a tal creencia Palladio, a través del carácter fragmentario de las ruinas arquitectónicas de los antiguos romanos y del estudio del tratado De architectura de Vitruvio, buscase la restauración del lenguaje clásico en su arquitectura.

Por tal motivo se dilucidará si la noción palladiana de disegno puede contemplarse como fuente de conceptualización en la arquitectura desde el punto de vista de la composición, el fragmento, la memoria, el legado y el patrimonio. Esto permitiría explicar ciertos fenómenos, hasta ahora no tomados en cuenta, que iluminarían a su vez el diseño actual y los procesos cíclicos de interpretación de las ideas, formas y espacios arquitectónicos.

Antes de hablar sobre lo expuesto previamente, es necesaria una breve explicación acerca de la recepción de la obra palladiana en el contexto histórico-cultural del Renacimiento mediante la percepción de Daniele Barbaro y Giorgio Vasari, lo que servirá como punto de partida para reconstruir el tema de la Antigüedad y el proceso creativo en Palladio, puesto que esos humanistas hablaron en sus tratados acerca de la teoría y la praxis de dicho arquitecto, haciendo hincapié en la idea de la innovación referida al estudio e interpretación de la teoría y la arquitectura clásica.

En sus Vite, Vasari expresó lo siguiente de Palladio: "excelente arquitecto moderno, [...] sus obras son bellísimas [...] no diré otra cosa de él, porque todo esto se dará a luz en el manuscrito de Palladio [I quattro libri], donde estarán impresos dos libros de los edificios antiguos y uno de sus bellas invenciones que ha construido" (Vasari 18781885 [1511-1574]: 531). ${ }^{3}$ Esta concepción vasariana es significativa, ya que definió su obra con el término italiano moderno, lo cual significó para los humanistas la buona maniera moderna, es decir, la buona maniera greca antica restaurada (cfr. Panofsky 1975: 73).

se tradujera como diseño o dibujo, afectaría y restringiría el concepto, uso y sentido que se le dio en el Renacimiento. Sobre un estudio del concepto humanista de disegno en la teoría arquitectónica del Renacimiento italiano y la problemática de su traducción, cfr. Solís 2015: 218-359.

${ }^{3}$ De aquí en adelante, las traducciones del italiano al español son de la autora. 
Por su parte, en I dieci libri dell'architettura Barbaro no sólo valoró la colaboración de Palladio en su tratado, ${ }^{4}$ sino que puso en evidencia la manera en que éste interpretó y estudió sistemáticamente la teoría arquitectónica vitruviana y los monumentos antiguos a través del disegno:

Para los disegni de las imágenes relevantes utilicé las obras de Andrea Palladio, [...] es quien mejor ha comprendido la verdadera arquitectura de la Antigüedad, ya que no sólo ha asimilado sus hermosos y sutiles principios, sino que también los ha llevado a la práctica, tanto en sus exquisitos disegni de las plantas, alzados y secciones, como en la realización de numerosos y magníficos edificios; son obras que rivalizan con las de los antiguos, dan luz a los modernos y despertarán la admiración de las generaciones venideras. Y en lo que respecta a Vitruvio, ha explicado e interpretado adecuadamente, con una gran habilidad de la mente y la mano, el arte y la construcción [...] y todos aquellos edificios cuyas proporciones responden a las más hermosas y ocultas razones; él es quien con juicio ha seleccionado por toda Italia los más bellas formas de los antiguos y medido todas las obras que de ellos se conservan (Barbaro 1987 [1567]: 64).

Tales reflexiones sacan a la luz la dialéctica entre tradición e innovación, ${ }^{5}$ a la que se suma la idea de la invención respecto de la afinidad electiva y la estética de la empatía en la arquitectura, puesto que Barbaro puso de relieve el proceso de selección de los monumentos que les interesaron como testimonios de su pasado. Más aún, puntualizó que esto lo documentó Palladio mediante los dibujos en proyección ortogonal, los cuales representan la interpretación renacentista del nexo conceptual y estético en imágenes, no sólo de la teoría y las descripciones de las estructuras clásicas de Vitruvio, sino también de los levantamientos arqueológicos que hizo de los edificios antiguos (cfr. Magagnato 1980: XI, XLVI, LIV; Mitrović 2002: 113-127). Es así como Barbaro relacionó las nociones de patrimonio y conservación tal como se concibieron en la cultura renacentista (cfr. Palladio 1980 [1570]: 462, 491, 494 y 503; Vecco 2007: 35, 37, 60, 71-72) con el legado del texto vitruviano y las ruinas, y, a su vez, habló del legado material e inmaterial de la arquitectura y los dibujos de Palladio.

Para establecer la idea del proceso creativo palladiano en relación con el disegno, Barbaro planteó que fue

\footnotetext{
${ }^{4}$ Es importante subrayar la relación intelectual y creativa que existió entre Barbaro y Palladio porque le permitió a este último tener una interpretación de la teoría vitruviana desde el punto de vista retórico, filosófico, filológico y geométrico que sólo un humanista como Barbaro podía darle (cfr. Tafuri 1987: XV).

${ }^{5}$ Utilizo el término innovación según la definición de Ernst Gombrich (1979: 281), el cual explica que el artista innovador lleva a cabo análisis críticos que involucran la comparación sistemática de logros pasados con motivos presentes logrando nuevas composiciones de la forma y realizando un avance importante del que otros pueden partir.
}

este arquitecto de Vicenza quien mejor comprendió la arquitectura de la Antigüedad, al asimilar sus principios a través de la selección y de medir las más bellas formas de los antiguos. Además, afirmó, también que las interpretó y las llevó a la práctica tanto con los dibujos de sus proyectos como con la realización de sus edificios, estableciendo que hizo un análisis crítico de la Antigüedad. Esta noción de Barbaro es lo que explica la innovación en Palladio y alude también, por lo tanto, a la recepción de su arquitectura en el Cinquecento.

\section{Arquitectura y disegno}

Aquí conviene hacer notar el término italiano de disegno empleado por Barbaro, pues él mismo, así como Leon Battista Alberti y Vasari definieron en sus tratados el proceso creativo para, por un lado, estructurar un sistema y una visión intelectual de la arquitectura como una reflexión propiamente estética de ésta por su racionalidad discursiva y, por el otro, para determinar y explicar de manera didáctica los principios de la composición arquitectónica. En el Cinquecento, esta concepción se sustentó a partir del precepto italiano de disegno, pues se determinó como lo inteligible y lo visible respecto de los procesos mental y material del diseño arquitectónico (cfr. Ciaravino 2004: 45-50; Solís 2015: 323-351).

Es importante destacar que ese conocimiento derivó de los principios latinos de la dispositio y la inventio establecidos en De architectura por Vitruvio como categorías para la composición arquitectónica, lo cual formuló en referencia a la terminología clásica de specie dispositionis, ideae, figura y forma (cfr. Callebat 1994: 31-46; Ackerman 2012: 224; Solís 2015: 298-351), interrelación léxica y conceptual que tiene su origen en el proceso creativo de la forma del discurso de la inventio y la dispositio que Cicerón definió en su teoría retórica: Vitruvio lo trasladó a la arquitectura para resolver el problema del proceso creativo con relación al diálogo entre el momento intelectual y el momento de expresión del proyecto arquitectónico. Por ello, incluyó la inventio dentro de la dispositio, pues es donde se lleva a cabo la selección y composición de la forma que se traduce y expresa mediante las species dispositionis o ideae, es decir, los dibujos de la planta, el alzado y la sección. A la vez, lo utilizó como paradigma para formular la concepción estética del diseño arquitectónico sustentada en el principio de belleza de la tradición grecolatina.

De ahí que la noción renacentista de disegno se consideró como idea, diseño, invención y dibujo, y se vinculó con el concepto de belleza de la forma arquitectónica y como proceso creativo. En este sentido, Palladio la empleó constantemente en su tratado, puesto que en su contexto cultural implicó la teoría y la praxis de la arquitectura en referencia con el sistema de pensamiento del espacio arquitectónico que le confirió el método de la 
geometría a través del dibujo en proyección ortogonal (cfr. Magagnato 1980: XX-XXII; Mitrovic 2013; Solís 2015: 18).

El patrimonio antiguo: fragmento, ruina, memoria, selección y disegno

Ahora bien, al inicio de I quattro libri, Palladio distinguió sus referencias clásicas y contemporáneas:

Me dediqué al estudio de la arquitectura; y porque siempre fui de la opinión que los antiguos romanos [...] en el edificar bien con mucho han adelantado a todos aquellos que después de ellos vinieron, me propuse por maestro y guía a Vitruvio, el cual es el único escritor antiguo de este arte $[\ldots]$ así como de las observaciones de mí hechas de los restos de los edificios antiguos, y de las leídas en Vitruvio y en Leon Battista Alberti y en otros excelentes escritores que después de Vitruvio han escrito, incluso de las que yo mismo he puesto en práctica de nuevo (Palladio 1980 [1570]: 9).

Lo que importa subrayar aquí es que Palladio revitalizó la teoría vitruviana como su fuente clásica principal, sin embargo, cabe destacar que existen innumerables referencias no sólo al estudio de los tratados de Alberti y Barbaro, con los cuales completó su educación e interpretación de la teoría clásica, sino también las observaciones que hizo in situ de los restos de las estructuras romanas, las cuales llevó a la práctica. De este modo, clarificó su idea de la renovatio clásica, pues puso en evidencia los aspectos de la teoría y la praxis arquitectónica que tomó como modelos siguiendo su contexto cultural.

Este planteamiento de asimilación de lo antiguo en la teoría arquitectónica del Renacimiento se vinculó con el principio ciceroniano de imitatio en lo que concierne a la invención y la selección del modelo que se toma para interpretarlo en nuevas creaciones, pues Cicerón definió que éste no debe considerarse como una reproducción exacta de la realidad, sino como una imitación creativa (cfr. Cicerón, 1999: 2-3; Ackerman 2000: 9-16). En este sentido, es importante precisar que Palladio estableció el concepto de imitatio, tal como fue entendido en la tradición clásica y el Renacimiento, en tres sentidos: primero, la observación de la naturaleza que debe imitarse para extraer los principios de la belleza. Segundo, el estudio de los textos clásicos, pues él mismo afirmó que imitó a Vitruvio, y, por último, la imitación de los monumentos antiguos (cfr. Palladio 1980 [1570]: 19, 31, 37, 67; Puppi 1972; Boucher 2000: 304-305).

En este punto habría que añadir que Palladio también profundizó sobre un pensamiento que aparece constantemente en su discurso: el estudio arqueológico que hizo de los edificios clásicos, a los que calificó como ruinas [ruine]; en éstas encontró los preceptos de la arquitectura, lo cual tradujo a través del disegno:
He viajado muchas veces a Roma [...] donde con mis propios ojos he visto y con mis propias manos he medido los fragmentos [fragmenti] de muchos edificios antiguos, los cuales [...] representan todavía como estupendas ruinas [ruine] el claro e ilustre testimonio de la virtud y la grandeza romana [...] me puse también la empresa de escribir los principios necesarios que deben observarse en todos los bellos ingenios [...] y además de esto mostrar el disegno de muchas de aquellas construcciones que por mí han sido concebidos en diversos lugares, y de todos aquellos antiguos edificios que hasta ahora he visto. [...] Finalmente he reducido aquella perfección que me ha sido posible, y habiendo aprobado lo que está contenido en ellos [los fragmentos] con larga experiencia, me atrevo a decir que tal vez he dado tanta luz a las cosas de arquitectura en esta parte, que los que después de mí vengan podrán, con mi ejemplo [...] reducir con mucha facilidad la magnificencia de sus edificios a la verdadera belleza y gracia de los antiguos, derivada de la armonía de sus partes [...] con mis libros, podré vivir largamente [...] en la memoria de los que después de nosotros vengan (Palladio 1980 [1570]: 7-8).

La reflexión anterior es una síntesis de las ideas de Palladio y de su metodología proyectual en cuanto al estrecho vínculo entre tradición, invención e innovación. Por un lado, planteó la investigación que hizo de los fragmentos de la Antigüedad mediante la observación y la medición, lo cual le permitió comprender los principios compositivos de la forma clásica (cfr. Gros 2006). Por el otro, se refirió al tema de la enseñanza en relación con la función visual del lenguaje arquitectónico del dibujo en proyección ortogonal, que utilizó como método de diseño. A través del disegno de sus proyectos y edificios construidos, así como de los monumentos que seleccionó de los antiguos, Palladio dejó un claro ejemplo de cómo debe proyectarse.

Es importante resaltar que en este pasaje, y constantemente en su tratado, Palladio se refirió a los edificios de la Antigüedad como fragmentos, lo cual permite reconocer que para él representaban el testimonio del conocimiento intelectual, estético y arquitectónico antiguo que es posible reconstruir como partes de un todo. En otras palabras, se puede deducir que, a través de los procesos de ver, medir y dibujar, estos fragmentos se convirtieron en una reflexión mental y visual sobre la esencia del espacio clásico. De esta manera, Palladio contribuyó a un análisis teórico y sistemático de las ruinas de la Roma antigua que aplicó a sus proyectos, fijando así que el dibujo representado en I quattro libri... es la idea abstracta y la expresión arquitectónica que implica las cualidades espaciales de la forma.

A través del corpus de los levantamientos de los edificios de la Antigüedad que incluyó en su tratado, se explican visualmente los argumentos aquí expuestos. Ciertamente, si se confrontan los dibujos del Tempio di Marte Ultore (Figura 1) con los restos de dicho monumento (Figura 2), 


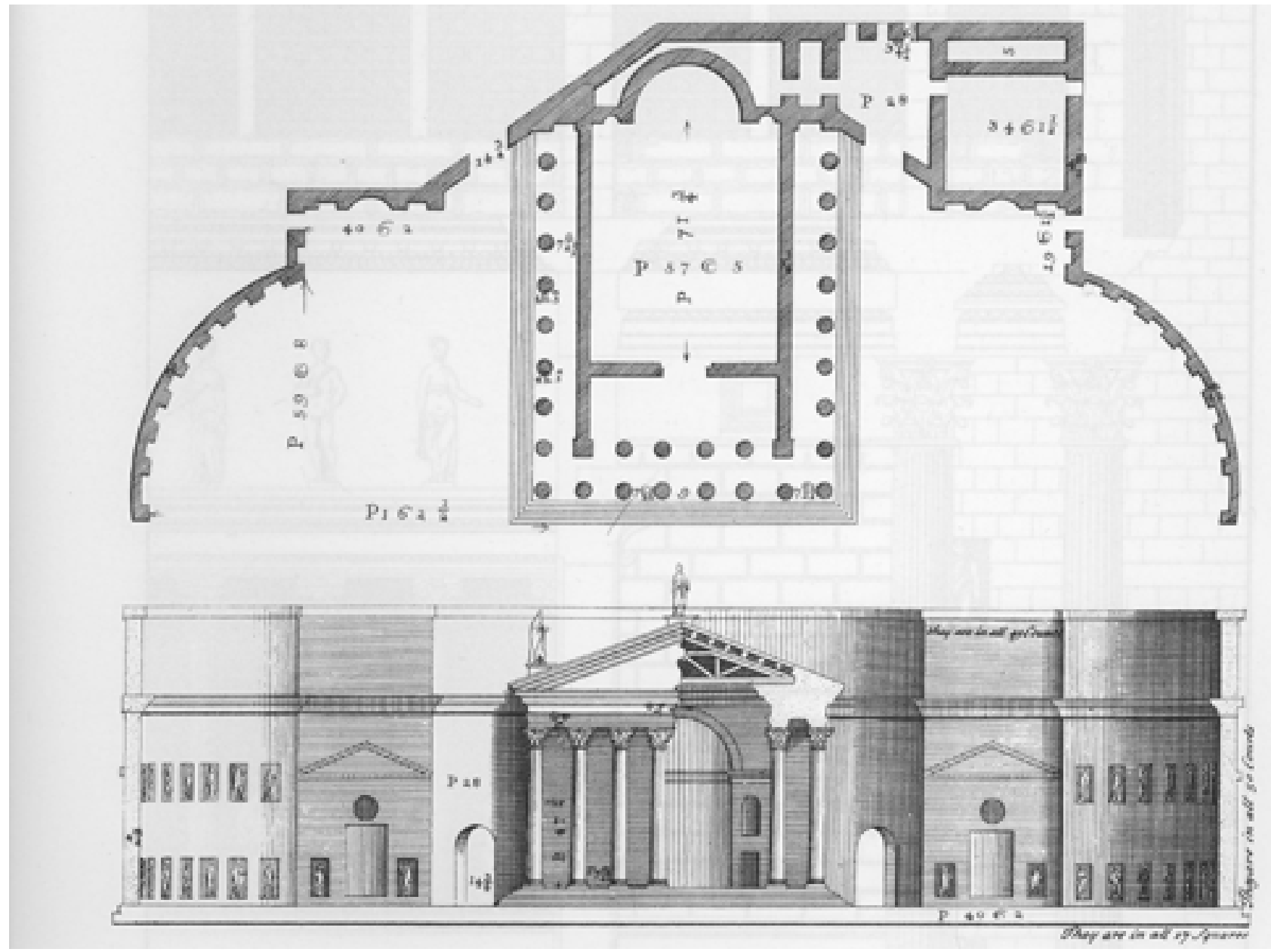

FIGURA 1. Planta y fachada frontal del Tempio di Marte Ultore de Andrea Palladio (Fuente: Andrea Palladio, 1980 [1570]: 269).

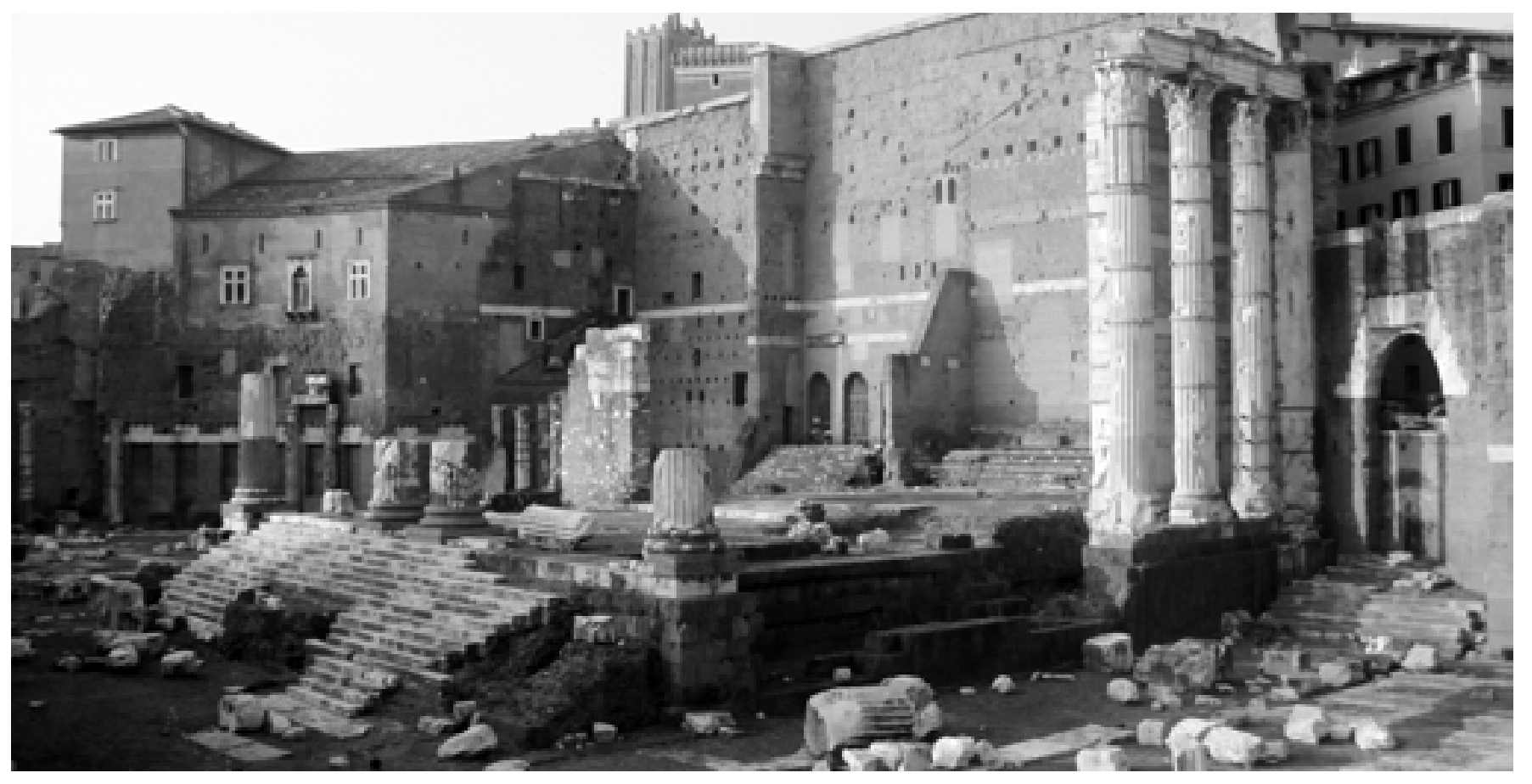

FIGURA 2. Tempio di Marte Ultore de Roma de 27 a.C. (Fotografía: Gabriela Solís Rebolledo, 2011). 
se observa no sólo la evidencia arqueológica que constituye la fuente conceptual de Palladio, sino también se comprende la manera en que surge la relación entre la visión, la memoria y la imaginación, pues mediante el análisis que realizó de los restos de este edificio quedan claras sus intenciones arquitectónicas. Por ejemplo, representó en una sola lámina la planta, la fachada y la sección del templo, mostrando simultáneamente con dichos dibujos las correspondencias del aspecto de la forma y del espacio interior que reinterpretó, como él mismo señaló, a partir de los vestigios de las ruinas (cfr. Palladio 1980 [1570]: 267-268).

En los dibujos se percibe la fachada y la sección del frontispicio. El mismo Palladio mencionó que representó el espacio del pórtico y la cámara interior con los ornamentos de su invención que agregó. Asimismo, se aprecian las ocho columnas de orden corintio, las esculturas en el frontispicio, el artesonado, el arquitrabe, el friso, el entablamento, la cornisa y el basamento, elementos que, consideró, conformaban el diseño de esta estructura, lo cual coincide con los fragmentos que se conservan de la estructura del Tempio di Marte Ultore.

No en vano Palladio enfatizó que redujo los principios de la belleza de la forma arquitectónica clásica mediante el $d i-$ segno. Además, con la publicación de sus dibujos dejó testimonio de la arquitectura clásica y de su propia arquitectura para los estudiosos que vinieran después de él y, en su memoria, pudieran recuperar y restituir dicho conocimiento.

Esto demuestra que Palladio fue totalmente consciente de la noción del dibujo como imagen y lenguaje de transmisión del conocimiento teórico y práctico de la arquitectura $y$, a su vez, como memoria visual, conocimiento que en el Cinquecento estaba íntimamente ligado al valor que se le concedía a la vista en referencia no sólo con el tema de la educación, sino también con la trascendencia del pensamiento arquitectónico (cfr. Argan 1980: 13). Sin embargo, habría que tener en cuenta que esta concepción renacentista sobre la importancia de la vista deriva de la tradición grecolatina, aquella que Cicerón formuló en sus escritos en relación con la figura o imagen que sólo será inteligible si está unida a un locus de la memoria, ya que estas formas entran por la vista y a partir de este sentido se puede retener con facilidad lo que se percibe mediante la imaginación (cfr. Cicerón 1995: 136-137, 202-216). En consecuencia, Palladio, siguiendo el contexto teórico renacentista, constituyó a la visión como un modo de conocimiento.

\section{Invención, proyecto y disegno}

En su tratado Palladio utilizó constantemente el término disegno, sin embargo, citaré dos pasajes donde lo vinculó con la invención, la idea de la permanencia de la forma de las reliquias [reliquie] y su conciencia de éstas como patrimonio antiguo en lo que se refiere a la imitación que hizo de los edificios clásicos:
Me dediqué a la investigación de las reliquias [reliquie] de los antiguos edificios, que han permanecido a pesar del tiempo y de la crueldad de los bárbaros [...] comencé a medir prolijamente y con suma diligencia cada parte [...] no hallando cosa que no hubiese sido hecha con razón y con bella proporción, para poder enteramente comprender el todo y en disegno traducirlo [...] Quedando muy obligado a aquellos [los antiguos romanos], que, de sus bellas invenzioni y de las experiencias hechas, nos han dejado los preceptos del tal arte, porque nos han abierto más fácil y expedito camino a la investigación de las cosas nuevas, y de muchas que gracias a ellos tenemos conocimiento, que acaso serían desconocidas todavía (Palladio 1980 [1570]: 9, 11).

Al hablar del legado de la arquitectura de los antiguos, Palladio lo denominó como invenzioni, lo cual es significativo, ya que en la teoría humanista este término derivó del principio clásico de inventio, que se interpretó como descubrimiento o hallazgo y también como invención (cfr. Kemp 1977: 348-351). Entendido en este sentido, no hay duda de que la "bella proporción" de los monumentos de la Antigüedad fue el modelo para formular el concepto para sus proyectos, los cuales le dieron ideas para restituir las formas y preceptos clásicos según la nueva manera de hacer la arquitectura del siglo XVI. Esta asimilación crítica de las cualidades espaciales de las ruinas las tradujo y materializó, como él mismo mencionó, mediante el disegno. No obstante, también se puede admitir que la invención y los preceptos del arte de los antiguos le sugirieron nuevas soluciones e indudablemente se convirtieron en su programa para interpretar cómo componer all'antica. Esto lo trasladó a su obra arquitectónica a través de nuevas tipologías que en I quattro libri tradujo en imágenes: tanto los dibujos de la arquitectura clásica como sus propios diseños. De esta manera, estableció que para la investigación de las cosas nuevas es necesario la reflexión de los principios de la composición fundados en el conocimiento del pasado, la comprensión de su presente y la proyección en el futuro (Argan 1970: 9-23).

De este pasaje se desprende, además, que para Palladio los monumentos clásicos no son sólo un patrimonio cultural y herencia conceptual, sino un repertorio de formas e imágenes de permanencia, de conocimientos y de identidad que siguen viviendo en su contemporaneidad y que, como tales, deben preservarse y valorarse desde el punto de vista arqueológico, arquitectónico y estético. En consecuencia, el fragmento, la imitación y la invención aparecen vinculados en una práctica que es al mismo tiempo memoria y proyecto, estableciendo un complejo diálogo entre la tradición clásica y la innovación.

Viene al caso citar aquí el segundo pasaje en el que Palladio se dirigió de manera didáctica para hablar sobre el disegno de los fragmentos de los templos clásicos, lo cual, según él mismo hizo hincapié, ilustró en su tratado mediante los dibujos de la planta, el alzado y la sección en proyección ortogonal: 
He representado y descrito aquí aquellos fragmentos [fragmenti], conocimiento de la virtud y de la grandeza romana que han quedado de los edificios antiguos a una forma tal que los observadores de la Antigüedad tomen con placer y a los estudiosos de la arquitectura le pueda servir de utilidad grandísima, siendo así que se aprende mucho más de los buenos ejemplos en poco tiempo, al medirlos y ver en un pequeño plano los edificios enteros y todas sus partes [...] he puesto en disegno muchas de aquellas magníficas y maravillosas edificaciones antiguas [...] mostrando en figura las plantas, alzados, y secciones y todos sus miembros, agregando las medidas justas y verdaderas, han sido por mí con sumo estudio medidos (Palladio 1980 [1570]: 187-189).

Es notorio que Palladio confía en la capacidad y el conocimiento de los estudiosos de la arquitectura no sólo para leer este tipo de imágenes bidimensionales como representaciones de las formas tridimensionales que implican un proceso intelectual, sino también para imaginarlas desde diferentes lados a través de las figuras geométricas, las cuales describen la configuración espacial y las partes del edificio analizado. Ejemplo de lo antes expuesto lo constituyen los dibujos de la planta (Figura 3), de la fachada (Figura 4) y de la sección transversal (Figura 5) del Panteón. Con estas láminas manifestó su interés y conocimiento de esta estructura romana.

Lo dicho resulta más evidente si se comparan con el edificio construido (Figura 6), a partir de lo cual se puede demostrar que las figuras geométricas de la planta, la fachada frontal y la sección transversal, así como los detalles de los elementos arquitectónicos del espacio interior que dibujó de este monumento, representan su tridimensionalidad, pues a través de la interrelación entre dichas figuras se comprende su configuración y, por lo tanto, permite una lectura del espacio (Figura 7).

En el dibujo de la planta se puede ver claramente la disposición del pórtico rectangular con las ocho columnas en el frente y cuatro en los laterales, y la circunferencia que implica el cilindro y la cúpula. De igual manera, en los dibujos del alzado y la sección transversal se manifiesta el exterior e interior de este monumento: la fachada principal con su frontispicio, las columnas de orden corintio en el exterior y en el interior, el entablamento, el pórtico, la cúpula, el óculo, los casetones, los nichos con sus esculturas, los tabernáculos y las cornisas, entre otros elementos arquitectónicos. Lo significativo para el contexto presente es que Palladio documentó las formas y espacios clásicos mediante los dibujos de los fragmentos de las bellas invenciones, como las denominó, los que se convierten en una especie de teoría visual, si se toma en cuenta que él mismo planteó que los principios arquitectónicos de dichos monumentos están representados en las figuras.

Como se ha visto en la evidencia extraída del tratado palladiano, los dibujos representan su exhaustivo estudio del Panteón. Sin embargo, si se hace un examen de los dibujos de las reconstrucciones de Palladio de los antiguos

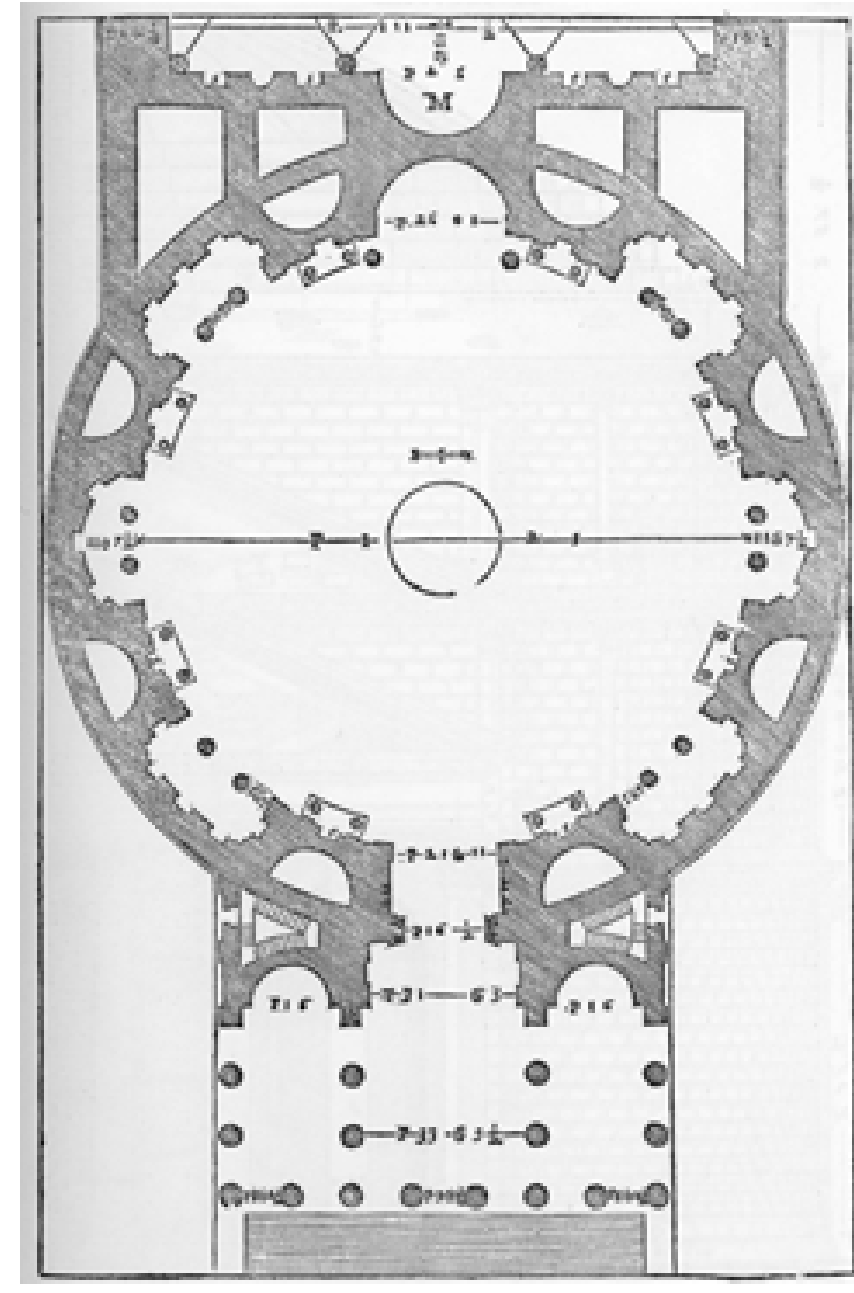

FIGURA 3. Planta del Panteón de Andrea Palladio (Fuente: Andrea PaIladio, 1980 [1570]: 339).

complejos monumentales se puede demostrar que se realizaron con intenciones proyectuales fundamentadas tanto en los restos clásicos como en las descripciones de Vitruvio, pues en varios de ellos la terminación de las partes faltantes de las ruinas se presenta como una especie de proyecto (cfr. Docci 2008: 27-28). Los dibujos de estas reconstrucciones vuelven explícito que lo que Palladio seleccionó para representar implicó para él la esencia de cada estructura clásica que después aplicó a su lenguaje formal.

Un ejemplo de este proceso se vislumbra en el dibujo de la reconstrucción del Tempio della Fortuna Primigenia (Figura 8), el cual revela numerosas analogías con el dibujo del Panteón, donde se pueden identificar las mismas soluciones estructurales y estéticas de este edificio, pues aparece de manera semejante como forma conceptual en los frontispicios dibujados en la parte inferior y superior de este complejo arquitectónico. En esta reconstrucción Palladio se centró en exponer otros aspectos que interpretó creativamente para sus proyectos en relación con los elementos arquitectónicos, el tratamiento del espacio 


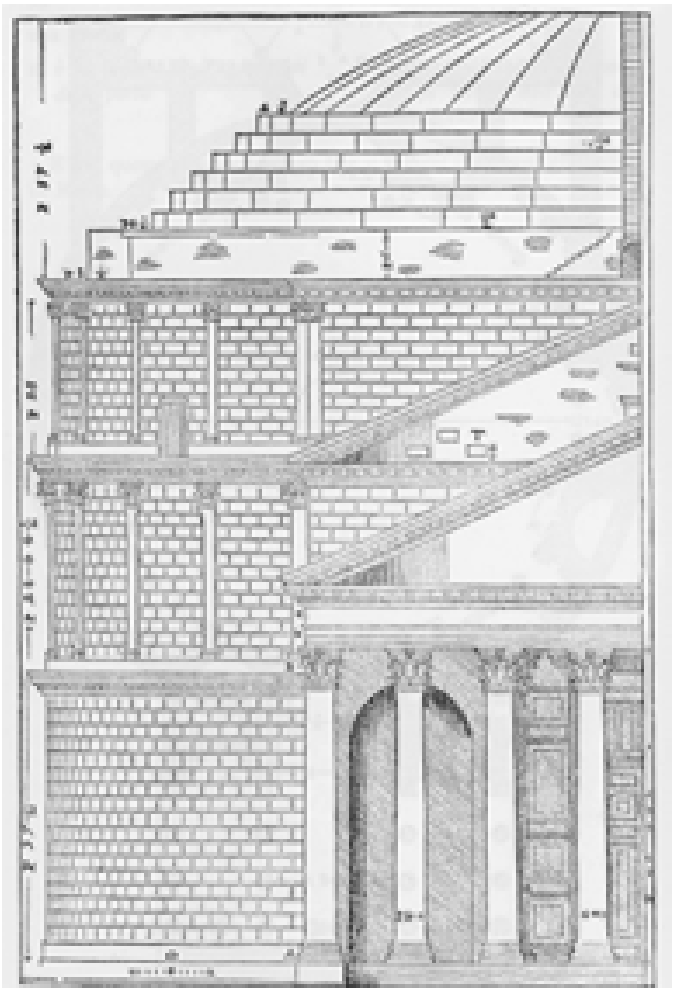

FIGURA 4. Detalle de la fachada frontal del Panteón de Andrea Palladio (Fuente: Andrea Palladio, 1980 [1570]: 340).

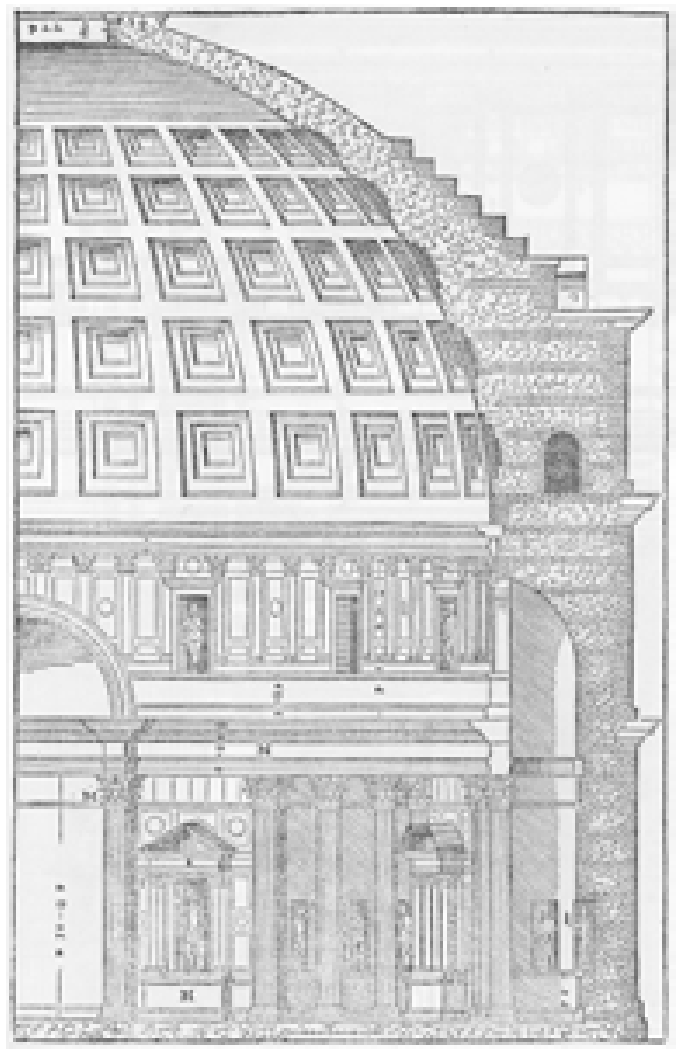

FIGURA 5. Detalle de la sección transversal del Panteón de Andrea Palladio (Fuente: Andrea Palladio, 1980 [1570]: 345).

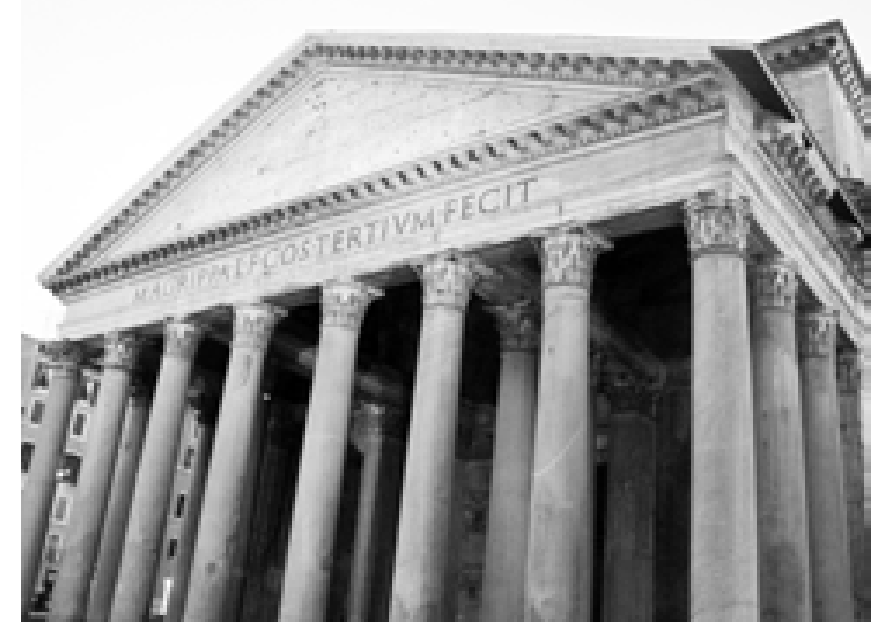

FIGURA 6. Fachada del Panteón de Roma de 27 a.C. (Fotografía: Gabriela Solís Rebolledo, 2011).

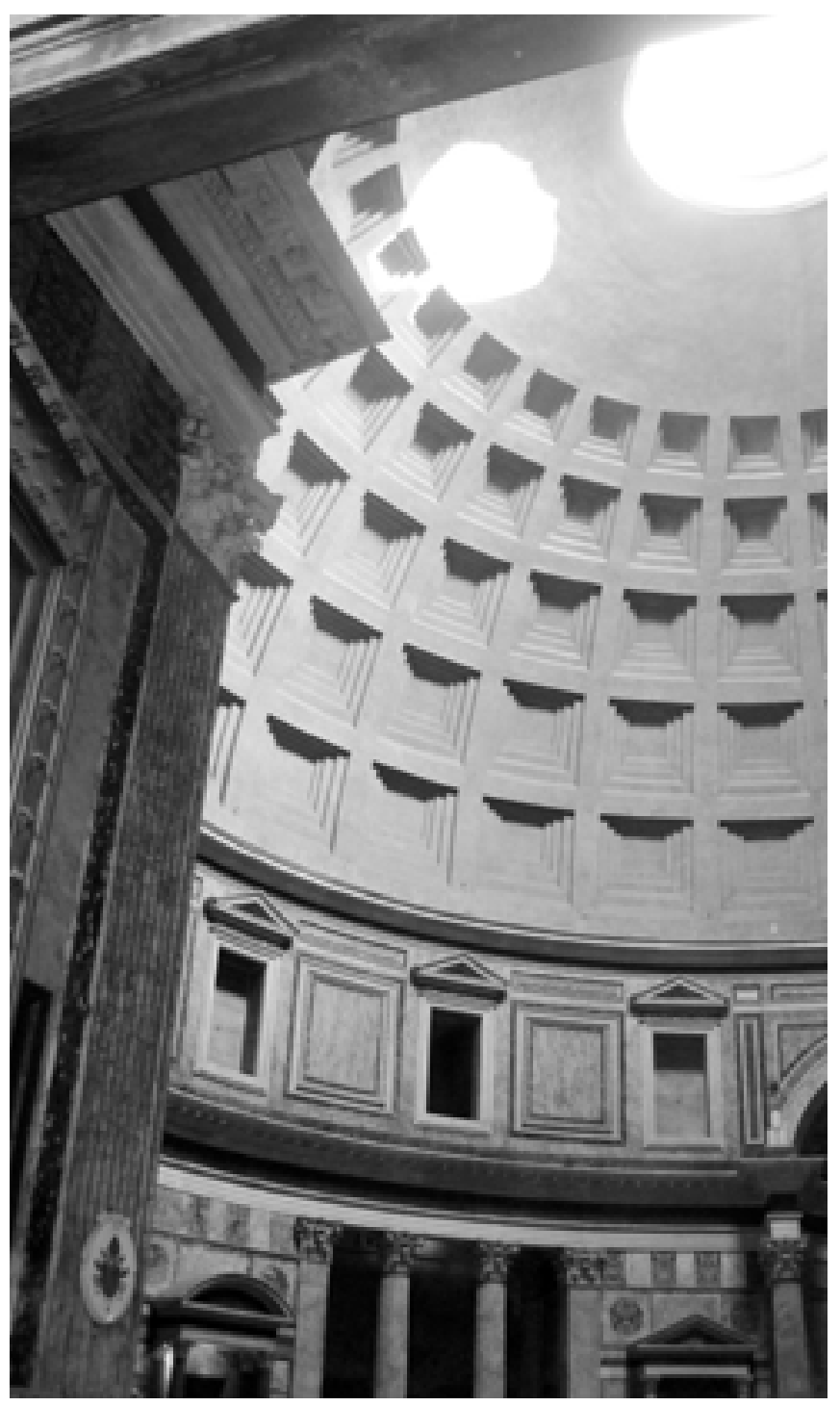

FIGURA 7. Detalle interior del Panteón de Roma de 27 a.C. (Fotografía: Gabriela Solís Rebolledo, 2011). 


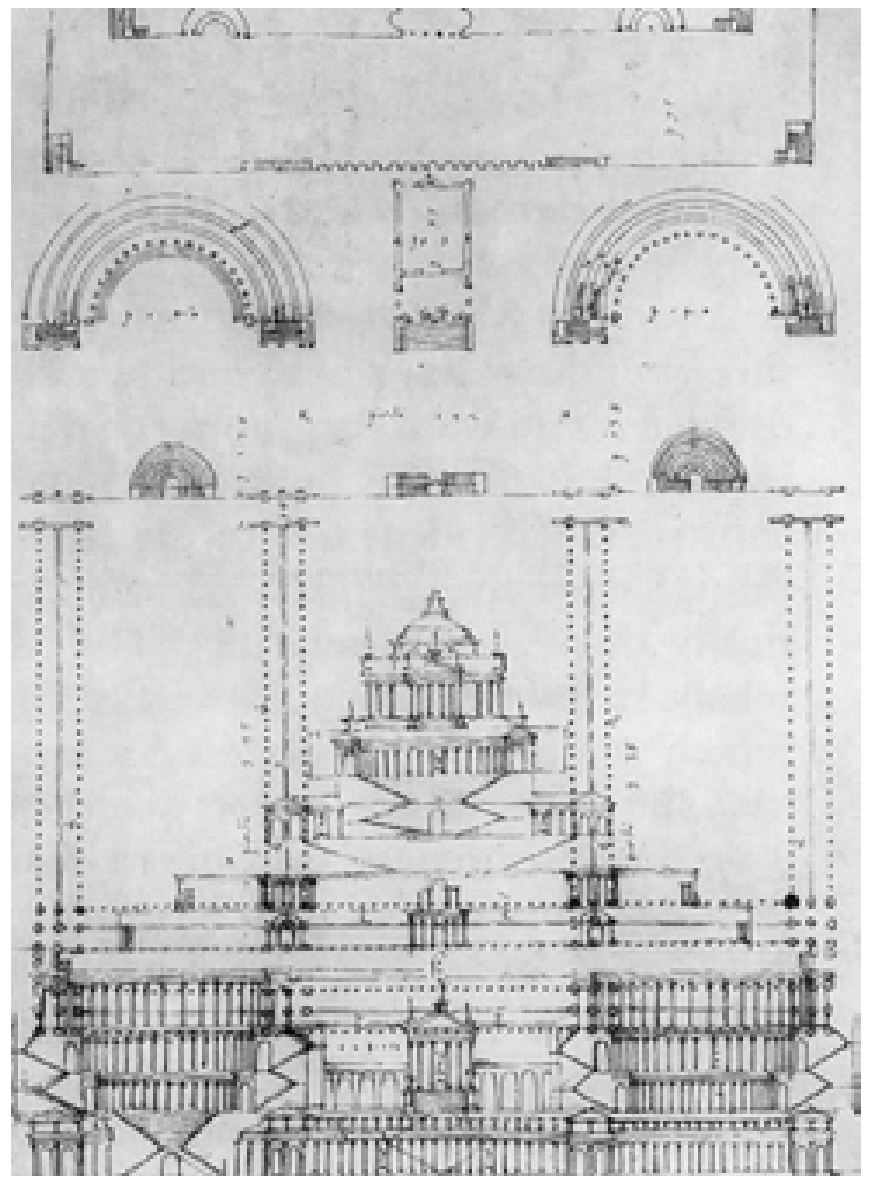

FIGURA 8. Planta y fachada frontal de la Reconstrucción del Tempio della Fortuna Primigenia de Andrea Palladio, 1560 (Fuente: Robert Tavernor, 1980: 76).

y del paisaje, los cuales se pueden percibir a partir de la síntesis que hizo de los restos materiales de esta ruina.

En el dibujo del alzado que dispuso en la parte inferior de la lámina hizo evidente la idea del espacio escenográfico que se infiere de la composición de esta estructura, pues reconstruyó que ésta se proyecta sobre el plano frontal del complejo arqueológico. Asimismo, a partir de la idea de las masas escalonadas, este monumento se integró a la imagen del territorio a través de representar la topografía del terreno, constituyendo, así, la relación con la naturaleza, esto es, la dialéctica con el paisaje, en la que la monumentalidad del conjunto que se insertó en un sistema de terrazas evidencia la selección y el vínculo con el lugar (cfr. D'Alessio 2011: 28-51). Por tal motivo, la solución de la simetría de la fachada se refuerza en todos los niveles de la estructura mediante el eje central del frontispicio ubicado en la parte inferior, el cual remata con el de la parte superior. De igual modo, en los dibujos de la planta y el alzado del templo se distingue claramente la disposición de las terrazas en relación con su profundidad y en correspondencia con los elementos que lo componen, lo que le confiere una jerarquía visual y genera el aspecto escenográfico del espacio.

Ahora bien, si se observan simultáneamente los dibujos de la reconstrucción del Tempio della Fortuna Primigenia y los que incluyó en I quattro libri, así como los del Panteón y los del Tempio di Marte Ultore, se aprecia que Palladio utilizó el frontispicio del templo en las fachadas no sólo como característica del legado de la Antigüedad, sino también como la reflexión clásica del tratamiento de la entrada con el propósito de crear una jerarquía espacial.

A la vez, estos dibujos sustentan que en el pensamiento y el proceso de diseño palladiano se efectúo una diferente percepción del espacio, la cual surgió a partir de su estudio de las reconstrucciones y de los edificios clásicos. Mediante la visión unitaria del dibujo en proyección ortogonal, Palladio mostró las diferentes maneras de interpretar el espacio antiguo. Es significativo que a través de esa estrategia visual, gracias a la cual se tiene la oportunidad de comparar los espacios que conforman dichos edificios, puso de manifiesto el concepto del espacio escenográfico clásico.

Estas imágenes son material suficiente para comprender el método de estudio de la Antigüedad y del diseño palladiano, pues en ellas puso de relieve su creatividad e imaginación que surgió de completar los fragmentos de las ruinas a partir de los preceptos clásicos, donde no sólo evidenció qué formas y elementos lo inspiraron para sus propios proyectos, sino también estableció que el disegno es el sistema de pensamiento y de expresión donde se crean las ideas. Esto se explica si se toma en cuenta que el dibujo le sugirió la reinterpretación, pues él mismo lo planteó al hablar sobre el tema de la invención, la variedad y las nuevas composiciones en la arquitectura, en conexión con los dibujos incluidos en su tratado, en los cuales subrayó que se pueden observar las variaciones que los antiguos hicieron en sus monumentos, razonamiento que le permitió utilizar el diseño clásico en combinaciones nuevas y deducir innovaciones de ellas (cfr. Palladio 1980 [1570]: 250).

Lo anterior demuestra la conciencia de Palladio sobre la distancia histórica, ya que a este proceso de interpretación, asimilación y transformación de las formas de la Antigüedad lo definió como la usanza nuova o bella maniera de hacer arquitectura, lo cual materializó en su obra construida, como es el caso de las tipologías de la villa, de la iglesia, del teatro y del palacio, entre otras, donde se pueden advertir estos conceptos clásicos aplicados a su diseño. ${ }^{6}$

\section{La Villa Barbaro: asimilación de la arquitectura de la Antigüedad}

El conocimiento basado en el aprendizaje adquirido a través de los estudios de las fuentes de Palladio se explica si se examinan los dibujos de sus proyectos en proyec-

\footnotetext{
${ }^{6}$ Según Magagnato, en Palladio la bella maniera consistió en la idea de restituir las formas de los antiguos según la bella maniera de los modernos (cfr. Magagnato 1980: XVIII).
} 
ción ortogonal y las descripciones que incluyó en I quattro libri..., como sucede con la Villa Barbaro (Figura 9), ejemplo de la reconstrucción tipológica de las soluciones de las villas clásicas (cfr. Forssman 1967: 248-249; Ackerman 1990: 108). Él mismo planteó que, debido al desconocimiento arqueológico de éstas y por falta de ejemplos concretos, consideró representar y describir el concepto de la villa all'antica con los dibujos de las obras encargadas por sus comitentes, e incluso puntualizó que sus villas están diseñadas a partir de los preceptos de la arquitectura de la Antigüedad del modo que enseñó $\mathrm{Vi}$ truvio (cfr. Palladio 1980 [1570]: 12, 172).

En efecto, Palladio, para expresar en su tratado la composición arquitectónica y documentar las referencias formales y conceptuales de la Villa Barbaro, eligió representar los dibujos de la planta y el alzado de todo el conjunto arquitectónico como resultado de un complejo proceso de abstracción. Los dibujos permiten tener una lectura simultánea del diseño de los espacios y las relaciones geométricas de las partes del edificio; en la lámina incluyó, asimismo, el texto que la describe, donde se preocupó por definir el programa arquitectónico, su funcionamiento y la estrecha relación entre la naturaleza y la arquitectura, lo que es una innovación de las villas palladianas. ${ }^{7}$

En la Villa Barbaro (Figura 10) se manifiesta la asimilación clásica del espacio escenográfico, de los elementos arquitectónicos y del tratamiento del paisaje que deriva de sus estudios de los monumentos y las reconstrucciones clásicas (cfr. Argan 1970: 172-179; Puppi 1973: 314318; Wittkower 1983: 11-15; Gardini 2008: 61-68), pues Palladio la diseñó a partir de la planta con énfasis en el plano frontal, tomando en cuenta la disposición de los espacios en función de su profundidad, lo que le confiere a la villa una jerarquía compositiva y determina la relación entre el cuerpo principal, las barchesse, los palomares y el paisaje Véneto. Además, en la fachada retomó el concepto clásico de simetría, el cual se acentúa en todos los niveles de la estructura mediante el eje central del frontispicio con su orden jónico y las esculturas en el frontón, solución actualizada por él del repertorio de los monumentos de la Antigüedad (Figura 11).

Al mismo tiempo, a la construcción principal le anexó una secuencia de muros, jardines, arcadas y escaleras, con lo que reforzó la idea tanto de lo escenográfico como de la extensión del paisaje, al adaptarse a la pendiente de la colina. El paralelismo entre arquitectura y paisaje que adquiere la villa se ve reforzado desde el inicio del terreno por el camino ascendente que remata con dos escalinatas del acceso principal de la casa barbariana, dispuestas por Palladio a lo largo del eje del conjunto y que insinúan la topografía del lugar (Figura 12).

Al confrontar los dibujos y la arquitectura de la Villa Barbaro con los del Tempio della Fortuna Primigenia o los

\footnotetext{
7 Para la descripción de la Villa Barbaro en I quattro libri, cfr. Palladio 1980 [1570]: 151-152.
}

del Panteón, se puede construir el puente entre la herencia de la arquitectura antigua y la arquitectura palladiana, pues la similitud es bastante notoria. No sólo se hacen evidentes las relaciones y las variantes de una afinidad formal, sino que también es análoga la conceptualización espacial. Por ejemplo, en la villa se puede percibir lo que retomó de estas estructuras: el bloque central que se asemeja a la tipología del templo clásico, el pórtico, las esculturas ubicadas en los laterales de las escaleras y en la parte superior del entablamento las escaleras enmarcando el acceso principal del edificio, la aplicación de la simetría como eje compositivo de la fachada, la monumentalidad del conjunto, el tratamiento del paisaje en conexión con la integración a la topografía del terreno y a la naturaleza, y el proceso de visualización del espacio escenográfico.

Asimismo, de los dibujos se infiere la asimilación del monumental frontispicio clásico. No se puede negar que Palladio lo utilizó como modelo en sus fachadas: él mismo expresó que para formular tal invención tomó como fundamento que los antiguos lo utilizaron en los edificios privados, concepción que él dedujo tanto de las descripciones vitruvianas como de las ruinas (cfr. Palladio 1980 [1570]: 151, 152). Precisamente, el frontispicio es uno de los elementos característicos de la arquitectura palladiana, innovación que aplicó a los proyectos de las villas y a los palacios, idea que responde a los criterios humanistas en lo relativo a lo estético y lo monumental, con la finalidad de indicar el acceso principal, crear una jerarquía espacial en la fachada frontal, articulando la totalidad del edificio. Después de todo, es difícil no ver en los dibujos y en la arquitectura de Palladio el proceso de síntesis y deducción de los principios de la arquitectura clásica donde se identifica la cita y el legado de la Antigüedad.

\section{Reflexiones finales}

A través del disegno, Palladio estableció el proceso de abstracción del lenguaje clásico como el propio, en virtud de lo cual fijó un diálogo dinámico entre la memoria y la creatividad, entre la historia y su contemporaneidad. Ello implicó que retomara las ruinas de la arquitectura de la Roma antigua con el propósito de fundamentar su teoría y recuperar mediante los fragmentos una parte del patrimonio cultural perdido; de esta manera, puso de manifiesto la interpretación, la permanencia, el modo de transmisión, de recepción y de apropiación de las ideas del lenguaje clásico. Para comprender todo ello, resultaba fundamental sistematizar el proceso de diseño, pues de su selección para crear valores de expresión propios dependía la manera en que restituía la herencia de la Antigüedad. Tal selección correspondía al proceso de empatía estética que se vincula con los intereses humanistas del Renacimiento y del propio Palladio.

Con ello se entienden mejor sus nociones de invención e imitación, pues concibió las ruinas de las estructuras 
La sottoposta fabrica è a Masera, ${ }^{21}$ villa vicina ad Asolo, castello del Trivigiano, di monsignor reverendissimo eletto di Aquileia e del magnifico signor Marc'Antonio fratelli de' Barbari.a Quella parte della fabrica che esce alquanto in fuori ha due ordini di stan-
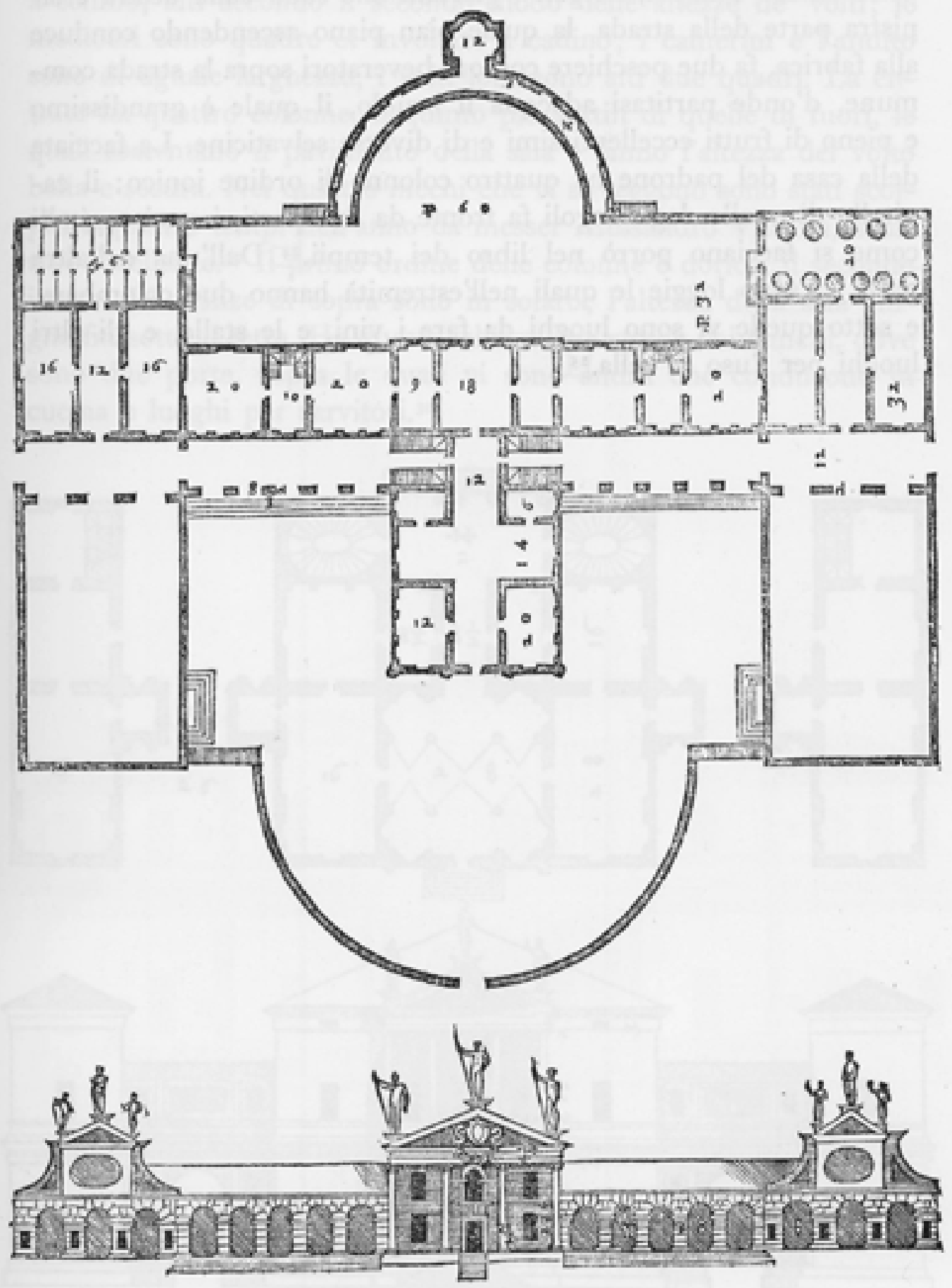

FIGURA 9. Planta y fachada frontal de la Villa Barbaro de Andrea Palladio, Maser-Treviso (Fuente: Andrea Palladio, 1980 [1570]: 151). 


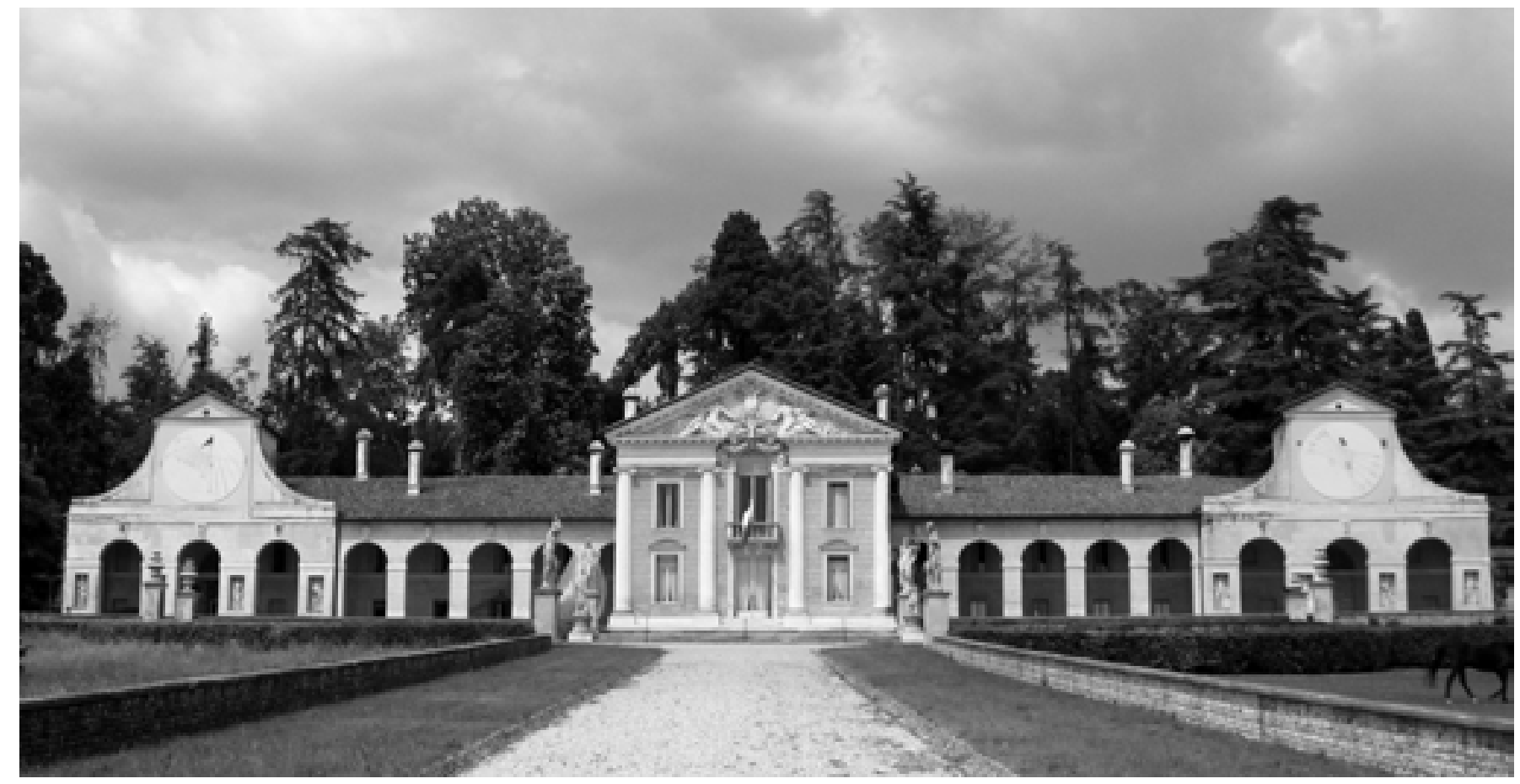

FIGURA 10. Fachada principal de la Villa Barbaro de Andrea Palladio y paisaje Véneto, 1554-1558, Maser-Treviso (Fotografía: Gabriela Solís Rebolledo, 2011; cortesía Villa di Maser, Italia, Patrimonio de la Humanidad-UNESCO).

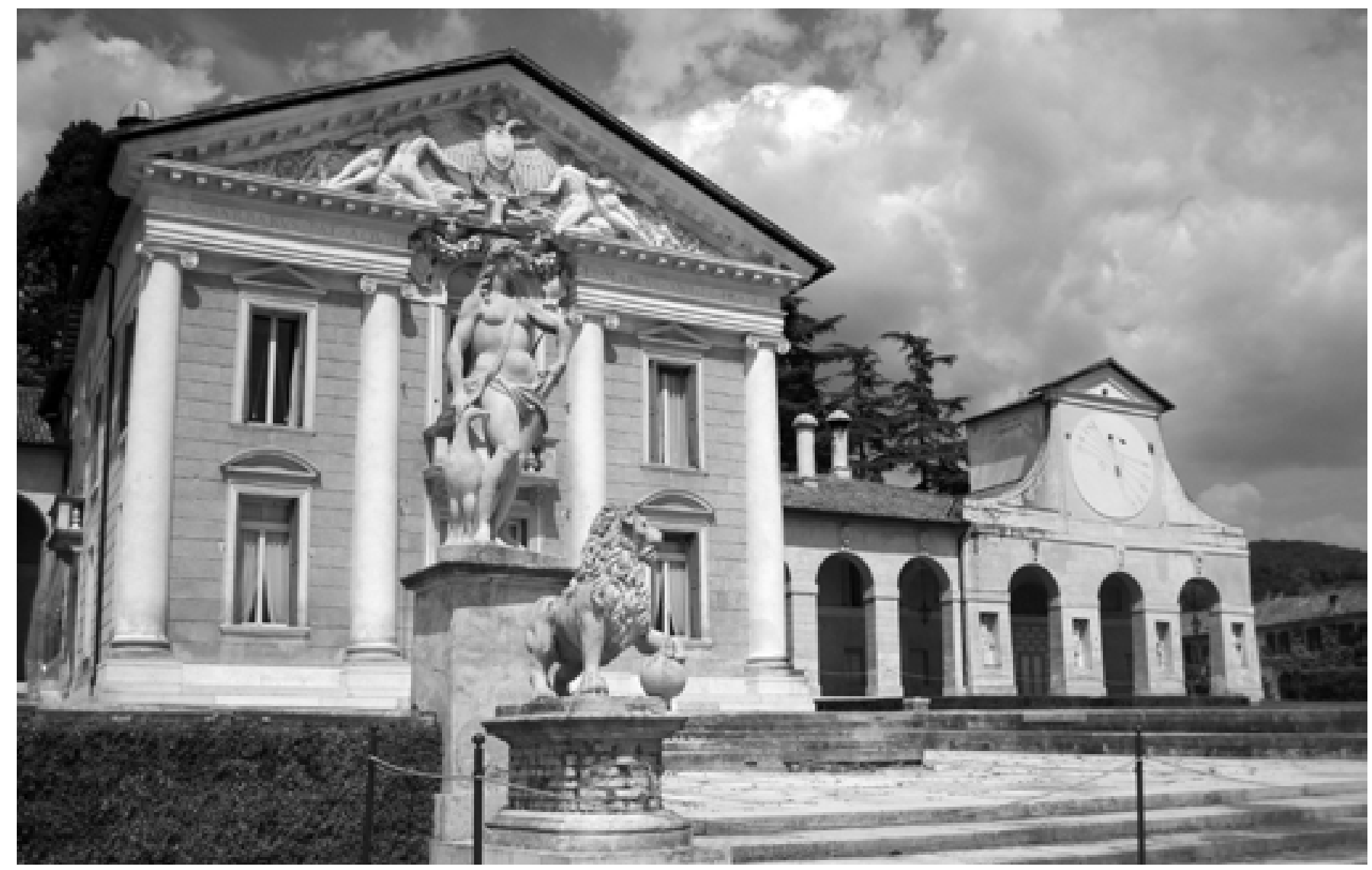

FIGURA 11. Frontispicio con orden jónico, barchesse y palomares de la fachada de la Villa Barbaro de Andrea Palladio, 1554-1558, Maser-Treviso (Fotografía: Gabriela Solís Rebolledo, 2011; cortesía Villa di Maser, Italia, Patrimonio de la Humanidad-UNESCO). 


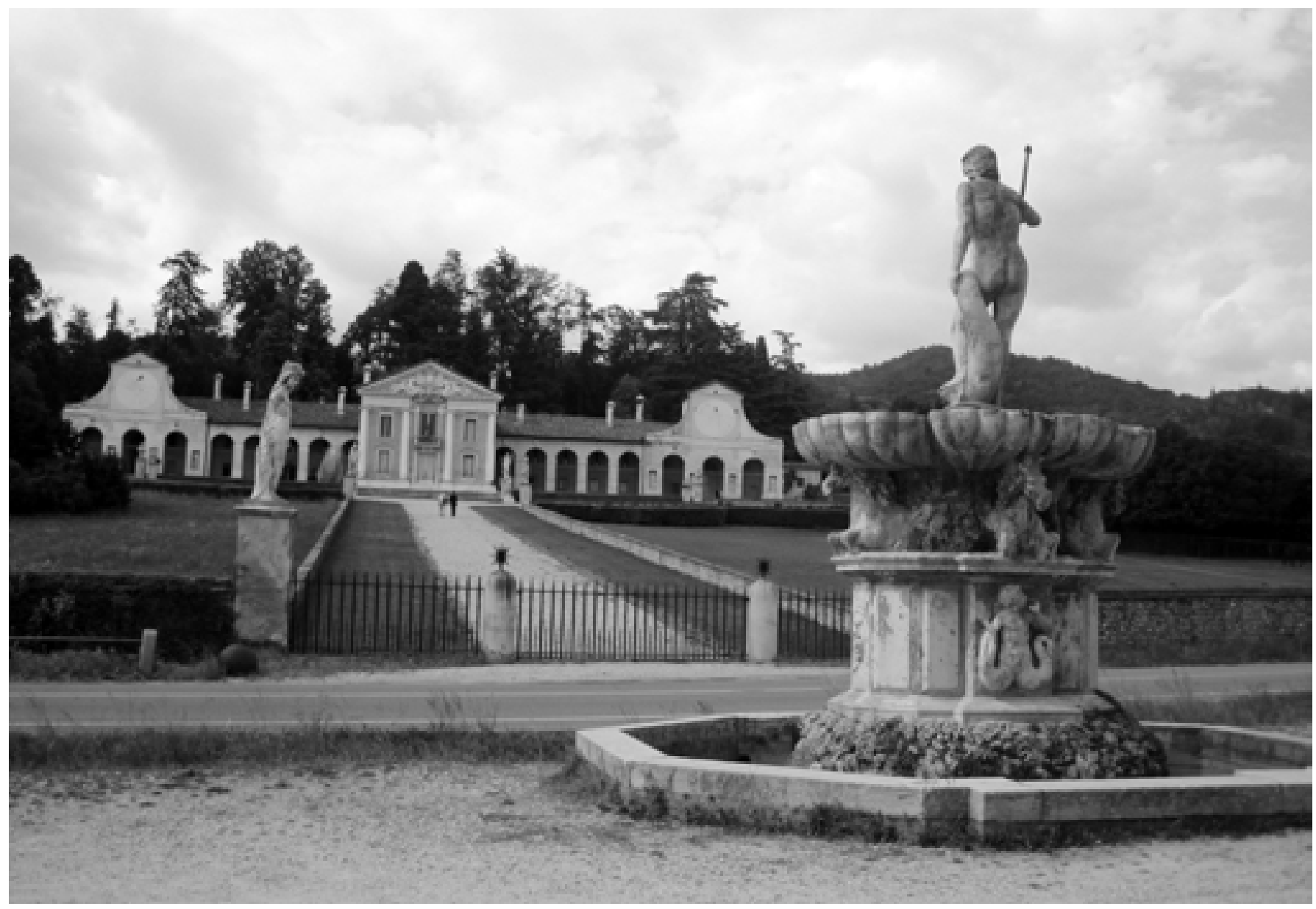

FIGURA 12. Acceso principal del conjunto de la Villa Barbaro de Andrea Palladio, 1554-1558, Maser-Treviso (Fotografía: Gabriela Solís Rebolledo, 2011; cortesía Villa di Maser, Italia, Patrimonio de la Humanidad-UNESCO).

clásicas susceptibles de nuevas interpretaciones no como una copia sino como un proceso creativo. En este sentido, el principio de disegno palladiano resulta válido en la actualidad en múltiples sentidos. Por ejemplo, como paradigma proyectual respecto a la reflexión crítica y el conocimiento de los conceptos del proyecto, y para el análisis e interpretación de formas del pasado, pues asocia los dibujos con las ideas y determina las relaciones visuales entre ellos, estableciendo, así, el proceso de reconstrucción y transmisión arquitectónica, en articulación con la continua vitalidad de la arquitectura tanto de la Antigüedad como palladiana.

Todas estas reflexiones pueden aplicarse a los problemas arquitectónicos actuales. Ejemplo de ello es el análisis crítico hecho por Peter Eisenman en su libro Palladio virtual sobre la interpretación de los dibujos de las villas en el tratado arquitectónico de I quattro libri..., el cual pone énfasis en la importancia de la dimensión visual de la teoría del proyecto (cfr. Eisenman 2015). Esto sirve como testimonio sobre la permanencia de Palladio en el pensamiento arquitectónico contemporáneo y acerca de su contribución continua a la disciplina respecto del proceso de diseño. Más aún, no hay que olvidar que la innovación en su obra surgió precisamente de la concepción que tenía acerca del pasado, lo que genera la trascendencia y legado no sólo de los principios y arquitectura de la Antigüedad, sino también de su pensamiento, dibujos y obra arquitectónica.

\section{Agradecimientos}

Esta investigación fue realizada gracias al Programa de Becas Posdoctorales de la Dirección General Asuntos del Personal Académico (DGAPA) de la Universidad Nacional Autónoma de México (UNAM), Facultad de Arquitectura (FA), Centro de Investigaciones en Arquitectura, Urbanismo y Paisaje (CIAUP) de la Universidad Nacional Autónoma de México (UNAM), cuyo responsable del proyecto de investigación de la beca posdoctoral es el doctor Ignacio del Cueto Ruiz-Funes, coordinador del CIAUP-FA, UNAM, así como a la doctora Isabel Medina-González. Agradezco también a los propietarios de la Villa di Maser, el doctor Vittorio Dalle Ore y a la condesa Diamante Luling Buschetti, quienes me facilitaron el acceso a Villa di Maser, en Treviso, región del Véneto, Italia, Patrimonio 
de la Humanidad desde 1996 por la Organización de las Naciones Unidas para la Educación, la Ciencia y la Cultura (UNESCO).

\section{Referencias}

\section{Ackerman, James Sloss}

1990 The Villa: Form and Ideology of Country Houses, Princeton, Princeton University Press.

2000 "Imitation", en Alina Payne, Ann Kuttner y Rebekah Smick (eds.), Antiquity and its Interpreters, Cambridge, Cambridge University Press, pp. 9-16.

2012 "Daniele Barbaro and Vitruvius", en James S. Ackerman, Origins, Imitation, Conventions. Representation in the Visual Arts, Cambridge, The MIT Press, pp. 217-234.

Argan, Giulio Carlo

1946 "The Architecture of Brunelleschi and the Origins of Perspective Theory in the Fifteenth Century", Journal of the Warburg and Courtauld Institutes, IX: 96-121.

1970 "La fortuna de Palladio", Bollettino del Centro Internazionale di Studi di Architettura Andrea Palladio (CISA), XII: 9-23. 1970 "The Importance of Sammicheli in the Formation of PaIladio", en Creighton Gilbert (ed.), Renaissance Art, Nueva York, Harper and Row, pp. 172-179.

1980 "Palladio e palladianismo", Storia dell'arte, 30 (40): 257-262.

Barbaro, Daniele

1987 I dieci libri dell'architettura de M. Vitruvio tradutti et commentati da Monsignor Barbaro [1567], facsimile con un saggio di Manfredo Tafuri e uno studio di Manuela Morresi, Milán, II Polifilo.

Boucher, Bruce 2000 "Nature and the Antique in the Work of Andrea Palladio", Journal of the Society of Architectural Historians, 59 (3): 296-311.

Callebat, Louis

1994 "Rhétorique et architecture dans le De architectura de Vitruve", en Le projet de Vitruve. Objet, destinataires et réception du De Architectura, Roma, Ecole Française de Rome, pp. 31-46.

Cellauro, Louis

2004 "Daniele Barbaro and Vitruvius: The Architectural Theory of a Renaissance Humanist and Patron", Papers of the British School at Rome, 72: 293-329.

Ciaravino, Joselita

2004 Un Art Paradoxal: la Notion de Disegno en Italie (Xvème-xvième siècles), París, Harmattan.

Cicerón, Marco Tulio

1995 Acerca del orador [De oratore], Amparo Gaos Schmidt (trad.), México, UNAM (Bibliotheca Scriptorum Graecorum et Romanorum Mexicana).

1999 El orador perfecto [Orator], Bulmaro Reyes Coria (trad.), México, UNAM (Bibliotheca Scriptorum Graecorum et Romanorum Mexicana).
D'Alessio, Alessandro

2011 "Spazio, funzioni e paesaggio nei santuari a terrazze italici di età tardo-repubblicana. Note per un aprocio sistemico al linguaggio di una grande architettura", en Eugenio La Rocca y A. D'Alessio (eds.), Tradizione e innovazione. L'elaborazione del linguaggio ellenistico nell'architettura romana e italica di età tardo-repubblicana, Roma, L'Erma di Bretschneider, pp. 28-51.

Docci, Mario

2008 "Disegni, progetti e proporzioni nell'opera di Andrea Palladio", Disegnare Idee Immagini: Rivista Semestrale del Dipartimento di Rappresentazione e Rilievo, 37: 27-93.

Eisenman, Peter 2015 Palladio virtuel, New Haven, Yale University Press.

Forssman, Erik

1967 "Tradizione e innovazione nelle opere e nel pensiero di Palladio", Bollettino del Centro Internazionale di Studi di Architettura Andrea Palladio (CISA), IX: 243-256.

Gardini, Gabriele

2008 "Andrea Palladio e la costruzione rinascimentale del paesaggio di villa", en Aldo De Poli, Chiara Visentin (eds.), Andrea Palladio e la costruzione dell'architettura, Università degli Studi di Parma, Facoltà di Architettura, Padua, II Poligrafo, pp. 61-68.

Gombrich, Ernst 1979 Arte e ilusión. Estudio sobre la psicología de la representación pictórica, Barcelona, Gustavo Gili.

Gros, Pierre 2006 Palladio e l'antico, Venecia, Marsilio.

Kemp, Martin

1977 "From 'Mimesis' to 'Fantasia': the Quattrocento. Vocabulary of creation, inspiration and genius in the visual arts", Viator, pp. 347-398.

Lücke, Hans-Karl 1994 "Alberti, Vitruvio e Cicerone", en Joseph Rykwert and Anne Engel (eds.), Leon Battista Alberti, Milán, Electa, pp. 70-95.

Magagnato, Licisco

1980 "Introduzione", en Licisco Magagnato y Paola Marini (eds.), Andrea Palladio, I quattro libri dell'architettura, Milán, II Polifilo, IX-LXVI.

Mitrović, Branko 2002 "Palladio's Canonical Corinthian Entablature and the Archaeological Surveys in the Fourth Book of I quattro libri dell'architettura", Architectural History, 45: 113-127. 2013 Visuality for Architects: Architectural Creativity and Modern Theories of Perception and Imagination, Charlottesville, University of Virginia Press.

Palladio, Andrea 1980 I quattro libri dell'architettura, Licisco Magagnato y Paola Marini (eds.), introd. de L. Magagnato, Milán, II Polifilo.

Panofsky, Erwin

1975 Renacimiento y renacimientos en el arte occidental, María Luisa Balseiro (trad.), Madrid, Alianza.

Payne, Alina Alexandra

1999 The Architectural Treatise in the Italian Renaissance: Architectural Invention, Ornament, and Literary Culture, Cambridge, Cambridge University Press. 
Puppi, Lionello

1972 "Palladio e l'ambiente naturale e storico", Bollettino del Centro Internazionale di Studi di Architettura Andrea Palladio (CISA), XIV: 225-234.

1973 Andrea Palladio. L'opera completa, 2 vols, Milán, Electa. Solís Rebolledo, Gabriela

2015 "El legado de la retórica clásica en I quattro libri dell'architettura de Palladio: didáctica, educación y trascendencia en su metodología proyectual y su obra arquitectóni$\mathrm{ca}^{\prime \prime}$, tesis de doctorado en historia del arte, México, Facultad de Filosofía y Letras, Universidad Nacional Autónoma de México.

Tafuri, Manfredo

1987 "La norma e il programma: Il Vitruvio di Daniele Barbaro", en I dieci libri dell'architettura de M. Vitruvio tradutti et commentati da Monsignor Barbaro [1567], facsimile con un saggio di M. Tafuri e uno studio di Manuela Morresi, Milán, Il Polifilo, I-XL.

Tavernor, Robert 1997 Palladio and Palladianism, Londres, Thames and Hudson.

Tobin, Richard F.

1979 "Leon Battista Alberti: ancient sources and structure in the treatises on art", tesis de doctorado en historia del arte, Michigan, Bryn Mawr College.

Vasari, Giorgio

1878-1885 Le vite de' più eccellenti pittori, scultori ed architettori scritte da Giorgio Vasari, pittore arentino, con nuove annotazione e commenti di Gaetano Milanesi, Florencia, G. C. Sansoni.

Vecco, Marilena

2007 L'evoluzione del concetto di patrimonio culturale, Milano, Franco Angeli.

Warburg, Aby

2005 El renacimiento del paganismo: aportaciones a la historia cultural del Renacimiento europeo, Madrid, Alianza.
Wittkower, Rudolf

1983 Palladio and English Palladianism, Nueva York, Thames \& Hudson.

1988 Los fundamentos de la arquitectura en la edad del humanismo, Madrid, Alianza (Alianza Forma).

\section{Síntesis curricular del/los autor/es}

\section{Gabriela Solís Rebolledo}

Facultad de Arquitectura (FA),

Centro de Investigaciones en Arquitectura, Urbanismo y Paisaje (CIAUP), Universidad Nacional Autónoma de México (UNAM), México

gabrielasolis7335@yahoo.com.mx

Licenciada en arquitectura (Facultad de Arquitectura [FA-UNAM], México), maestra y doctora en historia del arte (Facultad de Filosofía y Letras [FFyL-UNAM], México). En 2011 realizó estancia de investigación en el Kunsthistorisches Institut in Florenz Max-Planck ([KHI], Italia). Sus líneas de investigación incluyen arquitectura, teoría y diseño de la Antigüedad clásica, el Renacimiento italiano y de los siglos XVIII, XX Y XXI, especialmente, Vitruvio, Daniele Barbaro, Andrea Palladio, Étienne-Louis Boullée, Aldo Rossi y Peter Eisenman; filosofía, filología, retórica clásica, ciencia de la imagen e historia del arte. Desde 2004 hasta junio de 2017 fue docente en la Facultad de Arquitectura ([FA-UNAM], México). "La imagen como idea. Andrea Palladio y los dibujos de Aldo Rossi: Sala nuova del teatro La Fenice e Interno con teatro del mondo", Bitácora Arquitectura, 2015: 5465. Actualmente realiza una estancia posdoctoral en la Facultad de Arquitectura en el Centro de Investigaciones en Arquitectura, Urbanismo y Paisaje ([FA-CIAUP-UNAM], México) con el doctor en arquitectura Ignacio del Cueto Ruiz-Funes.

Postulado/Submitted: 07.01.2018

Aceptado/Accepted: 16.07.2018

Publicado/Published: 15.08.2018 